\section{Detailed recording of spontaneous rapid events*}

\author{
RONALD P. LARKIN \\ The Rockefeller University, New York, New York 10021
}

Events such as barpresses or licks, which may occur at any time during the day, are often clustered into bouts. The internal structure of such bouts can be recorded using an AM tape recorder, running the tape recorder only while bouts are in progress, and can later be analyzed off-line on a digital computer.

Analysis of the temporal characteristics of repetitive behavior requires that the animal behave while being monitored by a recording device. One approach has been to leave the monitoring equipment running continuously and to record spontaneous behavior in an undeprived $S$ over a long period of time, usually at low resolution. Such studies have revealed remarkable consistencies over the course of a day (Kavanaugh, 1968; Wenner et al, 1970). Alternatively, one can deprive a $S$, guaranteeing occurrence of the behavior during a session of fixed length, and analyze the fine detail of the behavior (Ferster \& Skinner, 1957; Allison \& Castellan, 1970). However, if one wants to combine these approaches and study in detail the behavior of undeprived Ss over a long period of time, a data acquisition problem arises. The problem is to obtain high resolution without playing through miles of one's recording medium. In addition, automated analysis is desirable, since hand analysis is tedious and usually involves arbitrary decisions which can bias the data. In previous studies, automation has involved either (1) an expensive machine to store data in computer-compatible form (Barry et al, 1966), or (2) a dedicated on-line computer (Stroebel, 1970). This report describes a system of accurate recording of such data using common laboratory equipment and an off-line digital computer.

The method is suitable for recording all-or-none events which occur in rapid succession, are clustered in time into "bouts," and can be converted into electrical pulses, e.g., licking and barpressing. A bout of events is distinguished by a criterion: two events separated by a time interval less than the criterion are placed in the same bout and those separated by intervals greater than the criterion are

*The work was done while the author was supported by an NSF predoctoral fellowship. Willard Friedman and Robert Schor provided much helpful advice on programming, and Emil Becker graciously allowed the use of his equipment. placed in different bouts. In this system, the intervals between bouts are ignored and separate provision must be made for recording these long time intervals. The internal structure of bouts is recorded as pairs of times for each event: an ON time-the duration of an individual event (one tongue contact)-and an OFF time-the duration between events (between tongue contacts). The sum of an ON time and an adjacent OFF time is the period of the behavior (interlick interval), and its inverse is the rate (lick rate).

\section{METHOD}

The data are recorded on an AM tape deck with a remote start-stop device, or clutch, controlling the capstan. The clutch is activated by a programmable clock (Fig. 1), which starts when an event occurs and is reset by each succeeding event. When the clock times out (reaches the bout criterion), the clutch is released and the tape stops. By this means, the tape is stationary during periods when no events occur but runs continuously during bouts of events. Intervals between bouts are not recorded, but timing of events within individual bouts can be recorded with high accuracy. Each event appears on the tape as a constant-frequency tone burst (Fig. 2), which is produced by gating a continuous signal through a switch controlled by the animal.

In the current implementation, a laboratory audio oscillator plays an $8.5-\mathrm{kHz}$ sine wave into the input of the tape recorder through the normally open contacts of a Grason-Stadler drinkometer or through a gating circuit on a special solid-state drinkometer. Two tape recorders, an RCA vacuum tube model and a Magnechord Model 1048, have been used successfully. An Atcotrol $110-\mathrm{V}$ clock can be easily wired to activate the clutch.

A day's data are recorded at 3.75 ips on a 7 - or 10 -in. tape reel and later played into a digital computer for analysis. As the tape is played at $7.5 \mathrm{ips}$ into a single-channel comparator input, the $\mathrm{ON}$ and $\mathrm{OFF}$ times are clocked to 1-msec accuracy and stored on digital magnetic tape. The program, which runs on a $4 \mathrm{k}$ LINC-8 laboratory computer, performs preliminary analysis and gives a running display of successive ON and OFF times on the CRT. Transient noise is rejected by storing only $\mathrm{ON}$ and $\mathrm{OFF}$ times which are longer than $14 \mathrm{msec}$. Bouts are recognized and stored together on LINC tape by programming a criterion which is the same as (or slightly less than) the criterion set on the clock which controls the audio tape deck. Sense switch options allow "freezing" of the program, rejection of bouts containing inaccurate data, and scaling of the display. I have transferred the data to a PDP-15 general-purpose computer and plotted power spectra, histograms, and imitation cumulative records in FORTRAN.

\section{TESTS AND DISCUSSION}

The system has been used to record the licking behavior of rats drinking milk from a spout on an ad lib basis. In order to measure the daily pattern of bouts, another drinkometer is connected in parallel and is used to operate a circuit which records the time of onset, time of cessation, and size in licks of each bout on a printout counter. The sizes and durations of bouts can thus be compared to the audio tape records, and the general accuracy of the system can be verified. A typical day's data are presented in Fig. 3, showing good correspondence between the two independent measures.

A few licks are, however, lost by the audio tape system. This occurs in two places. First, the LINC-8 does not have buffered tape drives, so that licks are lost while a bout or a part of a bout is stored on LINC tape. This problem would not occur on most computers; even on the LINC-8, careful programming could minimize it. A more fundamental problem is the data lost by the tape deck as it comes up to speed at the start of a bout, a process which takes about $200-250 \mathrm{msec}$.

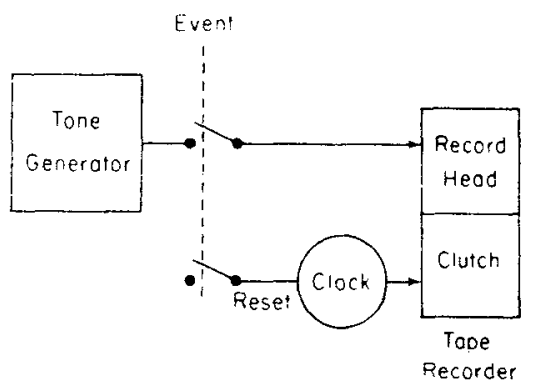

Fig. 1. Data acquisition system. 


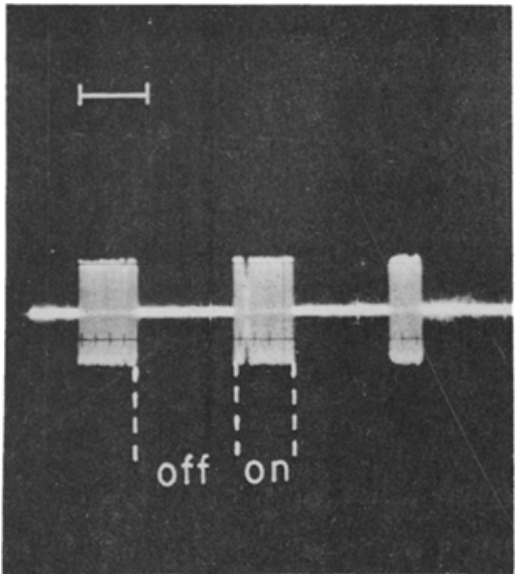

Fig. 2. Tape recording of individual licks. Each lick appears as a burst of $2-\mathrm{V} 8.5-\mathrm{kHz}$ sine waves; the $\mathrm{ON}$ and OFF times are indicated. Time mark is $.1 \mathrm{sec}$.

Since thousands of licks occur in a day and since the first few licks in a bout are usually slow and tentative, this problem has been ignored for the present application. If it were important, several steps could be taken. A time base from a crystal clock could be played into another channel of the tape recorder, allowing the computer to measure and compensate for the acceleration of the tape. A sensor such as a photocell could start the tape moving whenever the manipulandum or drinking tube was approached, so that a bout would be determined by proximity to the sensor instead of by the events themselves. The tape would thus already be moving when an event occurred. A more general and more expensive approach would be to build a digital delay line using a long shift register, with ON or OFF bits shifted into one end at a rate equal to the resolution desired. The tone would then be gated under the control of bits being shifted out the other end of the register, delaying the appearance of the tone on tape.

The temporal resolution of the basic approach is determined by the computer's clock, the tape playback and record speed, and the tone frequency. Two milliseconds of resolution was deemed adequate for the present application, so that computer time is saved by playing the tape back at double speed.

If an adequate signal is recorded on the audio tape and if the comparator is adjusted correctly, virtually no artifacts appear in the data. The computerized data have been used to produce imitation cumulative records on a Calcomp incremental plotter which match cumulative records taken on-line from the drinkometer circuit. The system has operated for weeks and recorded hundreds of thousands of licks without adjustment or repair.

A main advantage of this system is that it can be quickly made to operate using commonly available laboratory equipment. It requires a laboratory computer, but only for $15-30 \mathrm{~min} /$ day on an unscheduled basis.

\section{REFERENCES}

ALLISON, J., \& CASTELLAN, N. J. J. Temporal characteristics of nutritive drinking in rats and humans. Journal of Comparative \& Physiological Psychology,

\begin{tabular}{|c|c|c|c|c|}
\hline \multirow[t]{2}{*}{ TIME } & \multicolumn{2}{|c|}{ SIZE } & \multicolumn{2}{|c|}{ OURATION GIIM. } \\
\hline & Tape & POC & Tape & POC \\
\hline 1419 & 1164 & 1160 & 4.21 & 4.3 \\
\hline 1841 & 1733 & 922 & h 98 & 2.8 \\
\hline 2056 & & 803 & & 2.5 \\
\hline 0055 & 958 & 961 & 3.04 & 3.1 \\
\hline 0438 & 977 & 979 & 3.35 & 3.3 \\
\hline 0629 & 819 & 822 & 3.16 & 3.1 \\
\hline
\end{tabular}

Fig. 3. Comparison of taped and printout counter data. One day's milk drinking as measured by the audio tape system and by a printout counter. Durations of bouts are recorded only to $1 / 10 \mathrm{~min}$ in the latter. The second and third bouts were stored by the computer as one large bout due to a misadjustment of the programmable clock.

$1970,70,116 \cdot 125$.

BARRY, H., III, KINNARD, W. D., JR. WATZMAN, N.. \& BUCKLEY, J. A computer-oriented system for high-speed recording of operant behavior. Journal of the Experimental Analysis of Behavior, $1966,9,163-171$.

FERSTER, C. S., \& SKINNER, B. F Schedules of reinforcement. New York: Appleton-Century-Crofts, 1957.

KAVANAUGH, J, L. Program clocks in small mammals. Science, 1968, 161, $1256-1259$.

STROEBEL, C. F. Computer techniques for studying biological rhy thms: Quantitative chronobiology. Behavior Research Methods \& Instrumentation, 1970, 2 79-81.

WENNER, W. H., DOUHITT, T. C. BURKE, M. E., \& KEENAN, P, A. Observations on the regular recurrence of groups of spontaneous rhythmic oral activity in infants. In J. F. Bosma (Ed.) Second symposium on oral sensation and perception. Springfield, Ill: Charles C Thomas, 1970. Pp. 291-305. 